CARNETS DE Carnets de géographes

GÉOGRAPHES.

6 | 2013

Géographie des faits religieux

\title{
Alain Musset (2012) Le Syndrome de Babylone
}

Géofictions de l'apocalypse, Paris, Armand Colin

\section{Frédéric Dejean}

\section{(2) OpenEdition}

Journals

Édition électronique

URL : http://journals.openedition.org/cdg/954

DOI : $10.4000 /$ cdg. 954

ISSN : 2107-7266

Éditeur

UMR 245 - CESSMA

Référence électronique

Frédéric Dejean, «Alain Musset (2012) Le Syndrome de Babylone ", Carnets de géographes [En ligne],

6 | 2013, mis en ligne le 01 septembre 2013, consulté le 24 septembre 2020. URL : http://

journals.openedition.org/cdg/954; DOI : https://doi.org/10.4000/cdg.954

Ce document a été généré automatiquement le 24 septembre 2020.

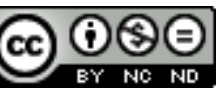

La revue Carnets de géographes est mise à disposition selon les termes de la Licence Creative Commons Attribution - Pas d'Utilisation Commerciale - Pas de Modification 4.0 International. 


\title{
Alain Musset (2012) Le Syndrome de Babylone
}

\author{
Géofictions de l'apocalypse, Paris, Armand Colin
}

Frédéric Dejean

\section{RÉFÉRENCE}

Alain Musset, Le Syndrome de Babylone, Géofictions de l'apocalypse, Paris, Armand Colin, 2012

1 Alain Musset a l'art de se saisir de sujets apparemment frivoles pour en révéler la profondeur au travers d'analyses minutieuses qui mobilisent les outils d'analyse des sciences sociales. En 2005, il publiait De New York à Coruscant. Essai de géofiction qui proposait une analyse du centre politique de l'Empire dans la saga Star Wars. Il récidive aujourd'hui avec Le syndrome de Babylone. Géofictions de l'apocalypse.

Comme pour son précédent ouvrage, Alain Musset prend appui sur une masse considérable de sources (romans, films, bandes dessinées et jeux vidéo) et propose une analyse géographique des mondes imaginaires déployés par ces œuvres. À un niveau supérieur - et c'est précisément là que l'approche du géographe prend tout son sens - il s'agit d'interroger la géographie de nos propres sociétés. Une telle démarche entérine l'intuition classique selon laquelle les œuvres ne sont pas des mondes clos, mais ont des choses à dire quant à notre propre condition, en particulier notre condition spatiale. Dans le cas présent, Musset postule que l'analyse de ces œuvres «permet de mieux comprendre les dysfonctionnements politiques, économiques et sociaux (...) dans un monde réel perçu comme toujours plus vulnérable malgré (ou à cause de) son développement technologique » (p. 23).

Dans Le syndrome de Babylone, Alain Musset s'intéresse à un topos de la science fiction, à savoir la fin du monde, sous toutes ces formes : déluge, attaque extra-terrestre, guerre nucléaire à grande échelle, ou encore changement climatique irréversible (décliné sous les deux extrêmes du froid polaire à la chaleur saharienne). Comme il l'écrit dans les 
pages introductives : «L'idée que le monde doit se terminer un jour ou l'autre, d'une manière ou d'une autre, occupe une place centrale dans les récits de science fiction dont les auteurs sont imprégnés de culture biblique» (p. 23). La dimension religieuse sous la forme de l'eschatologie chrétienne est en effet omniprésente dans les œuvres de science fiction dès lors qu'il est question de la fin des temps. Le titre de l'ouvrage ne trompe d'ailleurs pas puisqu'il est fait référence à Babylone, la cité pécheresse détruite par la colère divine ${ }^{1}$, et à l'apocalypse dont la déclinaison la plus fameuse, celle de Jean, clôt le grand récit biblique. L'apocalypse de Jean est un exemple parmi d'autres d'une vaste littérature dite apocalyptique dont les racines remontent au $6^{\text {ème }}$ siècle avant Jésus Christ. Bien que disparates, ces récits obéissent à une structure narrative commune : une révélation (sens premier du terme apocalypse) faite à un homme qui joue le rôle de trait d'union entre les ordres matériel et spirituel dans l'annonce d'un monde nouveau à venir. Car l'apocalypse n'est pas tant la fin $d u$ monde que la fin d'un monde. Même si Alain Musset n'entre pas en profondeur dans ces considérations, le plan de son ouvrage traduit néanmoins une telle dynamique :

4 La première partie («comment détruire le monde?») dresse la liste de toutes les modalités de destruction du monde contenues dans les récits de science fiction : elles peuvent être liées à des causes naturelles (virus mortel, mouvements terrestres, déluges...) ou avoir des causes strictement humaines, en particulier sous la forme de la menace nucléaire. Alain Musset montre notamment comment le contexte géopolitique - notamment la Guerre Froide - ont des effets sur les œuvres.

5 Dans la seconde partie l'auteur s'intéresse aux "villes et lieux de l'apocalypse ", en particulier Paris (« $6:$ quand la ville lumière s'éteint ») et New York (« $7:$ New York et la fin de la modernité »). Le chapitre 8 , "Icônes et géosymboles de l'apocalypses » offre une analyse de ces hauts lieux (la statue de la liberté, la tour Eiffel ou encore le World Trade Center) dont la destruction revient comme un leitmotiv. Enfin, le chapitre 9 interroge « la métaphore de la route».

6 La troisième partie, "Après l'Apocalypse : enfer ou renaissance ", rappelle qu'il y a une vie après l'apocalypse et qu'elle peut revêtir des formes multiples. Ainsi, elle peut être placés sous le signe du chaos («10. Mondes sauvages»), d’un retour aux sources («11. L'Exode urbain et le retour à la terre), ou encore d'une mise à l'écart, autant géographique que symbolique, du monde ancien («12. La solution arche de Noé »).

7 Au fil de ce parcours de plus de 300 pages Alain Musset parvient à alterner des analyses pointues - en faisant appel aux travaux des géographes, sociologues ou philosophes - et des séquences davantage descriptives. Celles-ci prennent parfois le dessus au point que le lecteur peut avoir l'impression d'être noyé sous un flot de références et se demande si le goût de l'exhaustivité - qui débouche parfois sur des répétitions - n'est finalement pas une entrave à l'analyse.

8 Pour autant, la lecture du livre reste un très grand plaisir et surtout, il suscite le désir de se plonger davantage dans la science fiction, genre trop souvent méprisé. De ce point de vue, l'ouvrage de Musset s'adresse autant aux connaisseurs qui y trouveront des clefs de compréhension à des lectures anciennes, qu'aux néophytes qui verront dans l'ouvrage une sorte de carte pour voyager dans l'univers foisonnant de la science fiction. 


\section{NOTES}

1. Nous lisons au Chapitre 18 (versets 2 et 3) de l'Apocalypse de Jean : «Elle est tombée, elle est tombée, Babylone la grande! Elle est devenue une habitation de démons, un repaire de tout esprit impur, un repaire de tout oiseau impur et odieux, parce que toutes les nations ont bu du vin de la fureur de son impudicité (...)».

INDEX

Thèmes : Carnets de lectures

\section{AUTEURS}

\section{FRÉDÉRIC DEJEAN}

Géographe - chercheur postdoctoral

Institut d'urbanisme

Université de Montréal 